\title{
Policy Direction of QoS Interworking and Management among Service Providers for Broadcast-Communication Convergent Services
}

\author{
Chin-Chol Kim ${ }^{1}$, Jong-Pil Jeong ${ }^{2}$ and Jae-Young Choi ${ }^{2}$ \\ ${ }^{1}$ National Information Society Agency, \\ NIA Bldg, Cheonggyechonno 14, Jung-gu, Seoul, 100-775, Korea \\ ${ }^{2}$ College of Information and Communication Eng, Sungkyunkwan University, \\ 2066, Seobu-ro, Jangan-gu, Suwon-si, Gyeonggi-do, 440-746, Korea \\ cckim@nia.or.kr, \{jpjeong, jychoi1001\}@skku.edu
}

\begin{abstract}
As the Internet technology evolves, the number of users enjoying not only communication services but also broadcast services through communication networks increases and the issues on quality of user experience $(Q o E)$ are on the rise. The convergent services are usually provided in an end-to-end manner via multiple heterogeneous carriers' network. Thus, a quality-of-service (QoS) management plan on the interworking section between carriers is needed because each carrier focuses on the QoS management within its own network boundaries. In this paper, we analyze the related standard documents and cases of other nations to set up a classification model of providers and scheme for QoS management among providers. With the results of the analysis, we provide a policy direction for the QoS interworking and management among providers in South Korea.
\end{abstract}

Keywords: QoS management policy, broadcast-communication convergent service, QoS interworking, QoS management

\section{Introduction}

As communication network technology has been advanced, the users' demand to get service of the voice, video and data through a single communication network is growing. Thus, each communication provider has provided broadcast-communication convergent service such as IPTV. The broadcast-communication convergent service asks the network to ensure a certain service level so that each communication provider currently establishes premium network separated from existing network or prepares the traffic differential processing function to handle quality assurance type service at least within its own network with priority rather than the best type service.

However, as environment provided by the convergent service has been changed such as open network and growth of the customers' demand for wireless IPTV, the broadcastcommunication convergent service will be provided through different provider network like Internet call. Thus, the interest for quality of interworking among providers is growing. Network interworking and quality management between providers are made through bandwidth via physical link connection and individual negotiation between providers in form of providing paths. The range of providers' quality management is mainly concentrated on its own network and service. Therefore, there is no quality management plan for different 
provider interworking sections such as quality management target, subjects, management methods and conflict prevention/ modulation for interworking sections.

If quality degradation factors occur in provider interworking section, the end user cannot get the promised quality of service (QoS), which may cause quality conflict between providers. Thus, end-to-end Service Level Agreement (SLA) is required to protect the users' right and prevent the quality conflict factors between providers. In terms of policy, the measures are required to induce the fair quality competition between providers and comply with quality level of service. In order to comply with quality of service (QoS) for interworking section between providers, new classification of provider type should be made from perspective of provider interworking rather than classification of provider licenses based on whether it has the base infrastructure. The establishment of technology and policy for quality interworking compliance item, quality indicator, quality allocation way and QoS management system field is urgently needed.

Therefore, this paper presents the standards to classify providers from the perspective of provider network interworking by utilizing related standards and cases for QoS management between different providers and establishes the plans for QoS management between providers. Through this, QoS interworking between providers and QoS management policy are suggested.

This paper is organized as follows; Chapter 2 describes essential items to be considered for QoS interworking between providers and QoS management policy. Chapter 3 presents policy direction which can be applied in environment in South Korea. Chapter 4 makes a conclusion.

\section{Considerations for determination on interworking QoS management policy}

This section describes the issues of operator classification model, QoS management guideline between operators, measures to allocate the interworking quality indicators and establishment of interworking QoS management system which should be considered for QoS management for interworking sections between different providers.

\subsection{Provider Classification Model}

Convergence type service like Internet TV oriented telecommunication environment brings the need of QoS management about specific section such as different provider interworking section in order to ensure QoS of end users. Service management structure is being changed from QoS management structure of a single provider to QoS management structure of various different providers. Since customers using convergence service receive the service through network of different provider, degradation of quality of one interworking provider may affect the entire service. Therefore, in order to assure the QoS of end users, study on provider classification model through interworking type analysis between providers should be conducted first. In other words, type classification between providers is based on provider license classification depending on the presence of base infrastructure rather than perspective of service interworking between providers such as key telecommunications service provider and special category telecommunications service provider. Thus, it is difficult to apply the policy for QoS management between providers in point of view of convergent service. Therefore, a study on new provider classification model to accept telecommunication environment and convergence type service in respective country is needed from the perspective of service interworking in order to regulate the quality of convergent service. 


\subsection{Guideline for QoS Management between Providers}

In South Korea, in order to assure QoS of its own subscribers, systematic QoS management is performed by using its own management policy and management system. However, since the management subject about different providers interworking section affecting user's end-to-end QoS is vague, QoS management measures are insufficient. A bond of sympathy on the need to manage different provider interworking section develops between domestic providers, but the guidelines such as management principle and range between providers which providers should comply with is lacking. Currently, SLA is signed between interworking operators to carry out the activity to maintain QoS level between providers, but there is a limitation in QoS assurance of end users through SLA between specific providers due to characteristics of IP based service. Thus, establishment of QoS management between providers including compliance and quality indicators between providers is required to assure QoS of end users.

\subsection{Measures to Allocate Interworking Quality Indicators}

Convergence services such as VoIP and IPTV require a certain level of QoS assurance. Thus, providers additionally establish the premium network separated from existing Internet traffic or traffic differential process function in which quality assurance type service is preferentially processed within network rather than best type service. However, convergence type service users join different network providers and get quality assurance type service between end-to-end users. In such cases, end-to-end path between users is configured via multiple provider networks. Service quality required in network directly affects network investment costs and operation costs. Therefore, the measures are required to establish the allocation of end-to-end QoS indicators between interworking providers with objective and systematic methods in order to provide quality assurance type service in interworking environment of different providers.

\subsection{Establishment of Interworking Service Quality Management System}

For effective dispute resolution between providers and assurance of users' rights and interests between providers, the establishment of QoS management system which can measure and manage the quality upon network interworking between providers is needed. In other words, required management procedures and functions including interworking protocols such as measurement principal, measurement point, measurement method and measurement cycle and detailed analytical techniques about measurement results required when traffic quality between networks is measured between different providers should be defined. In addition, through this, technical quality dispute elements are able to be defined to clarify the liability when quality degradation occurs between providers.

\section{Proposed policy Direction}

\subsection{Provider Classification Standards}

It is desirable to reflect network hierarchal structure presented in $\mathrm{BcN}$, convergence type network for realism, ease of implementation and expandability, provider classification standards presented in related cases to ensure objectivity and provider names presented in related international standardization organizations in the provider classification standards reflecting Korea' telecommunication environment as defined in Table 1. 
Table 1. Provider Classification Standards

\begin{tabular}{|c|c|c|c|}
\hline \multicolumn{2}{|c|}{ Classification } & Classification standards & Remarks \\
\hline \multirow[b]{2}{*}{ Service } & $\begin{array}{l}\text { Content } \\
\text { provider }\end{array}$ & $\begin{array}{l}\text { o Service provider to supply contents being used } \\
\text { in application service and edit this content }\end{array}$ & $\begin{array}{l}\text { o UK, EU Cases } \\
\text { o ITU-T } \\
\text { Standard cases }\end{array}$ \\
\hline & $\begin{array}{l}\text { Platform } \\
\text { provider }\end{array}$ & $\begin{array}{l}\text { o Provider who signs agreement to provide } \\
\text { service (terms of use). } \\
\text { o Provider who supplies the electrical signal on } \\
\text { network to provide application service except } \\
\text { content service. } \\
\text { o Telecommunication provider who leases } \\
\text { transmission capacity from network provider } \\
\text { and provides service. }\end{array}$ & $\begin{array}{l}\text { o UK, EU, } \\
\text { Singapore, } \\
\text { Australia cases } \\
\text { o GSMA } \\
\text { Standard cases }\end{array}$ \\
\hline \multirow[b]{2}{*}{ Network } & $\begin{array}{c}\text { Traffic } \\
\text { interworking } \\
\text { provider }\end{array}$ & $\begin{array}{l}\text { o Provider who operates or assigns } \\
\text { telecommunication network and system with } \\
\text { intention of providing telecommunication or } \\
\text { broadcast service. } \\
\text { o Provider who supplies environment of routing, } \\
\text { DNS, interconnection/ interworking to exchange } \\
\text { IP traffic targeting different providers. }\end{array}$ & $\begin{array}{l}\text { o UK, EU, } \\
\text { Singapore, } \\
\text { Australia cases } \\
\text { o GSMA } \\
\text { Standard cases }\end{array}$ \\
\hline & $\begin{array}{l}\text { Network } \\
\text { provider }\end{array}$ & $\begin{array}{l}\text { o Provider who leases or supplies } \\
\text { telecommunication network and system } \\
\text { facilities targeting service providers who supply } \\
\text { telecommunication service or broadcast service. } \\
\text { o Provider who holds supplementary facility } \\
\text { including transmission system, wire, wireless, } \\
\text { cable, satellite and Internet which electrically } \\
\text { delivers electronic signals. }\end{array}$ & $\begin{array}{l}\text { o UK, EU, } \\
\text { Singapore cases } \\
\text { o ITU-T } \\
\text { Standard cases }\end{array}$ \\
\hline
\end{tabular}

As shown in Table 1, content providers perform the production and edition of actual contents in terms of service and are equivalent to program providers in Korea. The classification standards for content providers assure the objectivity through analysis of EU, Ofcom case [1] and ITU-T Y.140.1 [2]. Platform providers sign the agreement to end users with service (i.e., Terms of Use). EU and Ofcom's electronic communication services, iDA's service based provider requirements and service provider requirement of ACMA are analyzed and provider classification system presented in GSMA IR.34 (2009) [3] are reflected to create the standards in this paper.

Traffic interworking providers of network operate and place the telecommunication network, system and facilities with the intention to provide telecommunication service or broadcast service. The classification reflects requirements for network providers presented in cases such as EU, Ofcom, iDA and ACMA based on the standards of IPX (IP Packet Exchange) provider requirements presented in GSMA IR.34 IPX. Finally, network providers lease or support the telecommunication network and system facilities targeting service providers who supply telecommunication service or broadcast service. The classification reflects the electronic communication network requirements of EU and Ofcom and network facility based provider requirements of iDA with reference of ITU-T Y.140.1. 


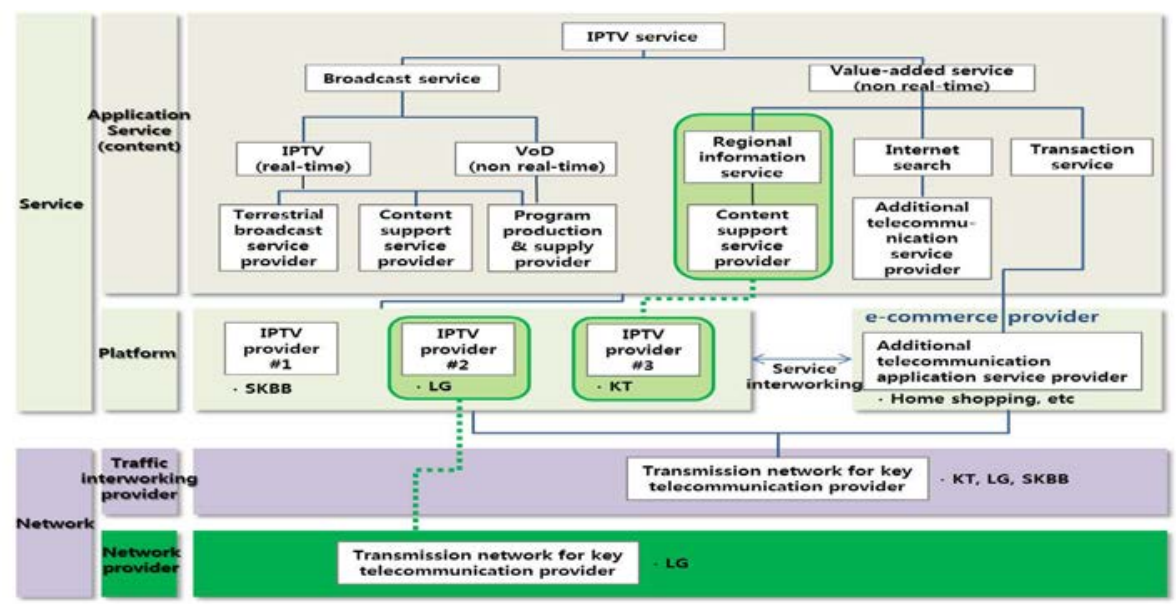

Figure 1. Classification of Providers about IPTV Service based on Provider Classification Standards in Korea

Table 2 classifies IPTV service providers according to provider classification standards presented above. Since IPTV service is currently provided through telecommunication infrastructure which each provider owns, there is no traffic interworking provider in Korea. Internet search services that domestic IPTV providers commonly provide are used as examples because value-added service is quite different from each IPTV provider like VoIP. In addition, IPTV providers are key telecommunication providers that hold transmission network according to current regulations and play a role as traffic interworking providers of value-added service as well.

Table 2. Hierarchical Classification of IPTV Service Providers based on Provider Classification

\begin{tabular}{|c|c|c|c|c|}
\hline \multirow{2}{*}{\multicolumn{2}{|c|}{ Classification }} & \multicolumn{2}{|c|}{ Broadcast service } & \multirow{2}{*}{$\begin{array}{c}\begin{array}{c}\text { Value-added service } \\
\text { (non real-time) }\end{array} \\
\text { Internet search }\end{array}$} \\
\hline & & $\begin{array}{c}\text { IPTV } \\
\text { (real-time) }\end{array}$ & $\begin{array}{c}\text { VoD } \\
\text { (non real-time) }\end{array}$ & \\
\hline \multirow[t]{2}{*}{ Service } & $\begin{array}{l}\text { Content } \\
\text { provider }\end{array}$ & $\begin{array}{l}\text { o Terrestrial } \\
\text { broadcast service } \\
\text { provider } \\
\text { o Program production } \\
\text { and supply provider } \\
\text { o Content service } \\
\text { provider }\end{array}$ & $\begin{array}{l}\text { o Program } \\
\text { production and } \\
\text { supply provider }\end{array}$ & $\begin{array}{l}\text { o Additional } \\
\text { telecommunication } \\
\text { service provider } \\
\text { - Portal provider }\end{array}$ \\
\hline & $\begin{array}{l}\text { Platform } \\
\text { provider }\end{array}$ & o IPTV provider & o IPTV provider & o IPTV provider \\
\hline \multirow[b]{2}{*}{ Network } & $\begin{array}{l}\text { Traffic } \\
\text { interwor } \\
\text { king } \\
\text { provider }\end{array}$ & & & $\begin{array}{l}\text { o Key telecommuni- } \\
\text { cation service provider } \\
\text { - IPTV provider }\end{array}$ \\
\hline & $\begin{array}{l}\text { Network } \\
\text { provider }\end{array}$ & $\begin{array}{l}\text { o Some key } \\
\text { telecommunication } \\
\text { provider } \\
\text { - Line rental } \\
\text { provider }\end{array}$ & $\begin{array}{l}\text { o Some key } \\
\text { telecommunication } \\
\text { provider } \\
\text { - Line rental } \\
\text { provider }\end{array}$ & $\begin{array}{l}\text { o Some key } \\
\text { telecommunication } \\
\text { service provider } \\
\text { - Line rental provider }\end{array}$ \\
\hline
\end{tabular}




\subsection{Guidelines for QoS Management between Providers}

\subsubsection{Compliance Items between Providers}

In order to select compliance items between providers, compliance targets are classified into interworking between providers and QoS management. The availability, accessibility, interworking quality and integrity are derived as main compliance items by using ITIL [4] structure as shown in Figure 2. After that, key compliance items are selected from perspective of interworking between providers.

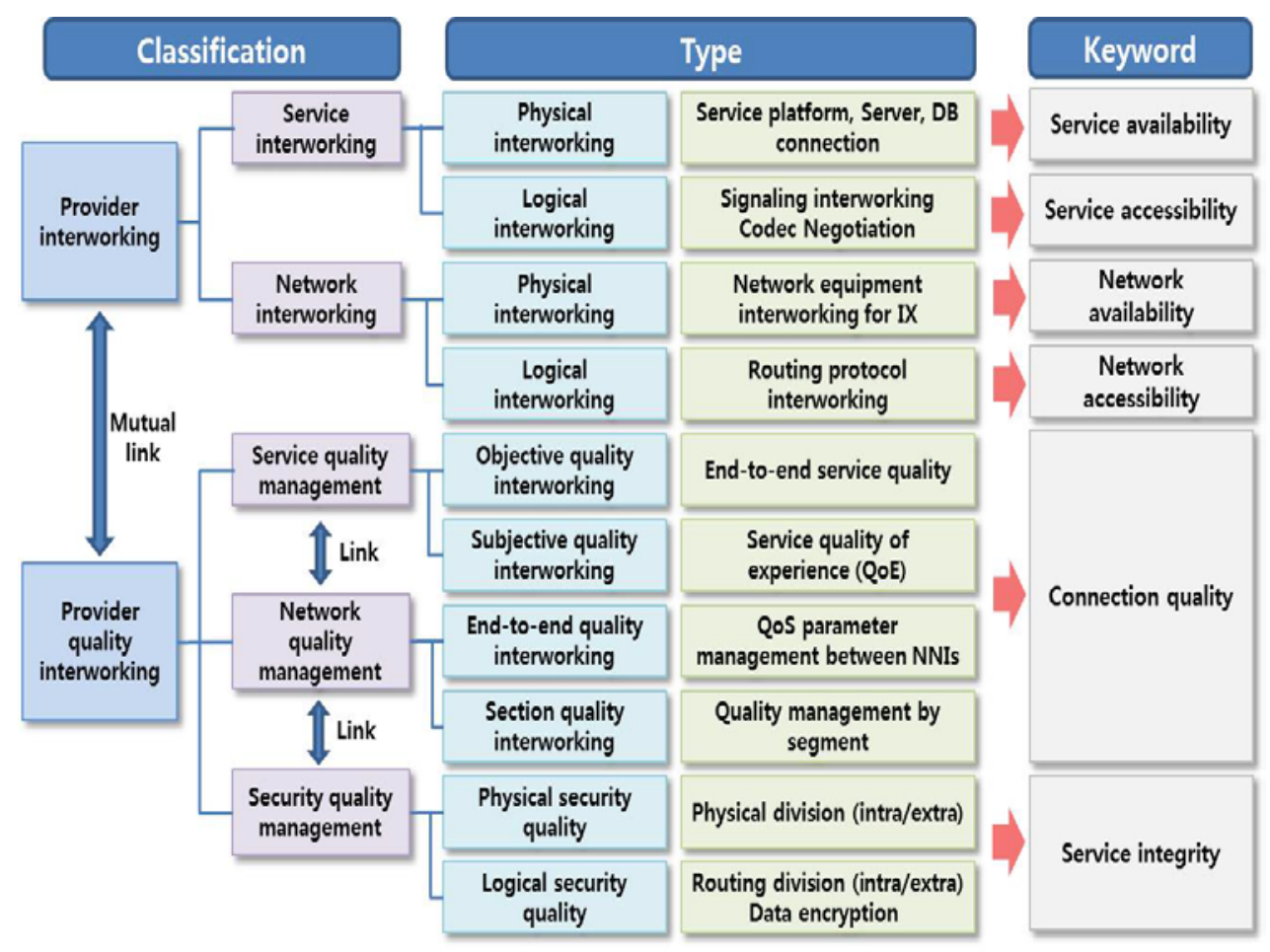

Figure 2. Main Compliance Items between Providers

As shown in Figure 2, the availability and accessibility are required as main items in terms of interworking between providers. From the perspective of physical interworking of service, physical elements such as platform or capacity of server may affect the service usage or quality. Thus, the assurance of service availability is needed. The service interworking from the logical perspectives implies signaling interworking for service usage.

The main items from the perspective of QoS management between providers require interworking quality and integrity. The interworking quality defined in GSMA IR.81 [5] implies that service quality is assured during the period when users use the service. Since the telecommunication environment is quite different from that of each provider, QoS management in interworking environment between providers including provided service and infrastructure should be carried out by each provider. Finally, since the assurance of aspect of integrity is required in order to prevent the degradation of transmission data and ensure the stability of network which a provider holds in provider interworking environment, security quality between providers is selected as a main item. 


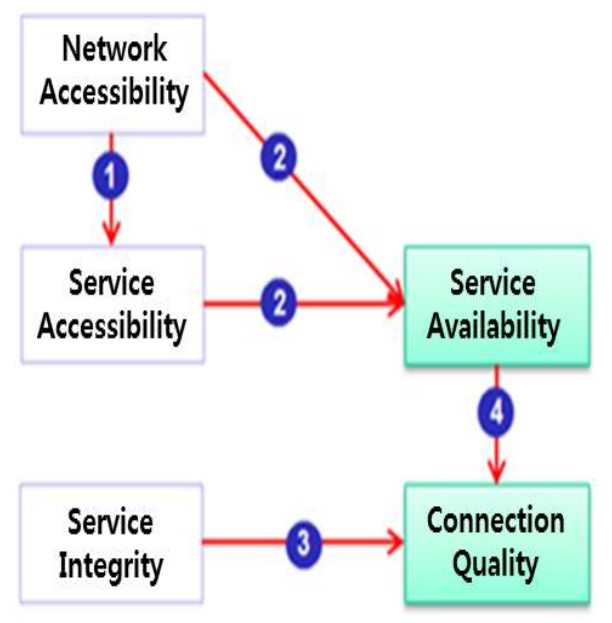

Figure 3. Linkage between Main Items from the Perspective of Interworking

As shown in Figure 3 and Table 3, it is necessary to select key items according to relationship between main items from the perspective of interworking for efficient service interworking and QoS management between providers. As shown in Table 3, interworking quality is needed for service availability and quality assurance for permanent service usage. Service availability assures that the access of users is always available within time agreed between user and provider. Interworking quality directly affects QoE and implies performance indicators of network hierarchy. Therefore, in order to ensure the QoE, additional definitions about interworking quality indicators are needed

Table 3. Relationship between Main Items from the Perspective of Interworking

\begin{tabular}{c|l}
\hline Classification & \multicolumn{1}{|c}{ Contents } \\
\hline (1) & $\begin{array}{l}\text { If access to network between provider is available, the service } \\
\text { interworking can be provided. }\end{array}$ \\
\hline (2) & $\begin{array}{l}\text { If network and service access between providers is assured, the } \\
\text { availability for respective service can be provided. }\end{array}$ \\
\hline (3) & $\begin{array}{l}\text { In case of download service, if degradation of provided data occurs, } \\
\text { retransmission of respective data occurs and then discomfort on service } \\
\text { usage of end users occurs. }\end{array}$ \\
\hline (4) & $\begin{array}{l}\text { If service usage is available, interworking quality assurance and } \\
\text { management between providers can be made. }\end{array}$ \\
\hline
\end{tabular}

\subsubsection{Interworking Quality Indicators}

Quality indicators between providers presented by related standardization organizations include time delay, jitter, packet loss and packet error but the notation by quality indicators is different $[6,7]$. Therefore in order to determine the proper quality indicators in domestic telecommunication environment, it should be based on the international standards to enhance the objectivity and professionalism of the quality indicators between providers. In order to reflect the reality, usage type of users and service interworking between providers should be considered. In order to monitor the quality of different provider interworking section, the ease of measurement should be considered. For example, quality indicators between domestic VoIP providers are selected based on different provider interworking type as shown in Table 4. 


\subsection{Quality Allocation Method}

Quality allocation method between providers requires the method to show the QoS level with the same condition regardless of scale of providers in order to form quality related fair competition structure between providers. In international standard ITU-T Y.1542 [8], quality allocation method is largely classified into static and dynamic methods. It is reasonable that quality allocation method between providers based on such telecommunication environment in Korea applies static uniform allocation method which evenly allocates end-to-end QoS requirements between providers regardless of size of network of provider and internal network structure. In other words, it is reasonable that government should accept demands of providers, present the quality standards by each grade, provide the guideline to present the instruction of implementation and management such as grade assignment of key service and promote the policy in the direction to maximize the autonomy of providers within the frame to encourage the voluntary participation of providers.

Table 4. Quality Indicators by Interworking Types of Different Providers Related to VolP Service

\begin{tabular}{|c|c|c|c|c|}
\hline Classification & Delay & Jitter & Packet Loss & Remark \\
\hline $\begin{array}{l}\text { Service provider } \leftrightarrow \\
\text { Service provider }\end{array}$ & \multirow{3}{*}{$\begin{array}{l}\text { End-to-end } \\
\text { One-way } \\
\text { Delay }\end{array}$} & \multirow{3}{*}{$\begin{array}{l}\text { End-to-end } \\
\text { Jitter }\end{array}$} & \multirow{3}{*}{$\begin{array}{l}\text { End-to-end } \\
\text { Packet Loss } \\
\text { Ratio }\end{array}$} & \multirow{3}{*}{$\begin{array}{c}\text { End-to-end } \\
\text { Service } \\
\text { Quality } \\
\text { Indicator }\end{array}$} \\
\hline $\begin{array}{l}\text { Service provider } \leftrightarrow \\
\text { Wired subscriber } \\
\text { network provider }\end{array}$ & & & & \\
\hline $\begin{array}{l}\text { Service provider } \leftrightarrow \\
\text { Wireless subscriber network } \\
\text { provider }\end{array}$ & & & & \\
\hline $\begin{array}{l}\text { Wired subscriber network } \\
\text { provider } \leftrightarrow \text { Wireless } \\
\text { subscriber network provider }\end{array}$ & \multirow{2}{*}{$\begin{array}{l}\text { Interworking } \\
\text { Section One- } \\
\text { way Delay }\end{array}$} & \multirow{2}{*}{$\begin{array}{l}\text { Interworking } \\
\text { Section Jitter }\end{array}$} & \multirow{2}{*}{$\begin{array}{l}\text { Interworking } \\
\text { Section } \\
\text { Packet Loss } \\
\text { Ratio }\end{array}$} & \multirow{2}{*}{$\begin{array}{l}\text { Network } \\
\text { Service } \\
\text { Quality } \\
\text { Indicator }\end{array}$} \\
\hline $\begin{array}{l}\text { Wired subscriber network } \\
\text { provider } \leftrightarrow \text { Wired } \\
\text { subscriber network provider }\end{array}$ & & & & \\
\hline
\end{tabular}

\subsection{Measures to establish QoS management system}

For interworking QoS management between providers, the measurement method for quality indicators should be established first. It is reasonable that mixed method[9] combining advantages of active/passive methods is applied as the measurement method for quality management between different providers to promote the policy to be applied in quality dispute. In addition, it is appropriate to promote the policy with the method to apply the hierarchical model as QoS management system for objective QoS management between different providers with consideration of QoS management structure (ITU-T Y.2173[10]) analysis and environment in Korea. In other words, the government selects measurement points about interworking section with consideration of QoS management range of existing network providers, defines and distributes data collection format by measurement cycles and providers to send the measurement results of each provider to QoS management system. 


\subsection{Dispute preliminary response and follow-up management plans}

It is reasonable that government establishes the quality related dispute resolution committee through benchmarking Ofcom and ACMA, and promotes policy to assure the rights and interests of users and encourage making a conclusion of dispute resolution between providers. In addition, it is reasonable that Ombudsman system is applied to check whether respective provider conducts it upon request of relevant agency and monitor whether a provider carries it out. In terms of system, dispute resolution knowledge DB is created to rapidly respond to a similar case to minimize the inconvenience to users.

\section{Conclusion}

This paper analyzes several international standards and cases, and presents QoS management policy directions between providers in broadcast-communication convergent environment with consideration of telecommunication environment in Korea. In order to do this, domestic provider interworking status is reflected and the provider classification standards, compliance items between providers and quality indicators between providers are presented. Quality standard allocation algorithm between providers, methods to configure QoS management system between providers and policy direction for dispute resolution between providers are proposed.

Results of this research can be utilized as reference materials for autonomous SLA between providers such as QoS management between providers and dispute resolution from perspective of providers. In addition, results can be utilized as basic materials to protect rights and interests of users and create voluntary quality QoS management environment guideline between providers from perspective of government. Lastly, these can be utilized as the reference material about quality related dispute resolution methods and procedures from perspective of users.

\section{Acknowledgements}

This research was supported in part by contribution of Korea Communications Commission and Next-Generation Information Computing Development Program through the National Research Foundation of Korea(NRF) funded by the Ministry of Education, Science and Technology (2012- 0006426). Corresponding authors: Jae-Young Choi and Jong-Pil Jeong.

This paper is the extended version of paper presented at International Conference on Information Science and Technology.

\section{References}

[1] OFCOM, "UK Broadband Speeds 2008" (2009).

[2] ITU-T Y.140.1 "Guideline for attributes and requirements for interconnection between public telecommunication network operators and service providers involved in provision of telecommunication services Series Y: Global Information Infrastructure, Internet Protocol Aspects and Next Generation Networks Global information infrastructure - General”, (2004).

[3] GSMA IR.34, "Inter-Service Provider IP Backbone Guidelines", V.4.6 (2009).

[4] itSMF,"ITServiceManagementbasedonITILVersion2" (2006).

[5] GSMA IR.81, "GRQ Measurement Implementation", V 1.0 (2009).

[6] GSMA IR.34, "Inter-service Provider IP Backbone Guideline", V4.1 (2007).

[7] ITU-T Y.1543, "Measurement in IP Network for Inter-domain Performance Assessment" (2007).

[8] ITU-T Y.1542, "Framework for Achieving End-to-End IP Performance Objectives" (2006).

[9] ITU-T Y.1543, “Measurements in IP networks for inter-domain performance assessment” (2007).

[10] ITU-T Y.2173, “Management of Performance Measurement for NGN” (2005). 


\section{Authors}

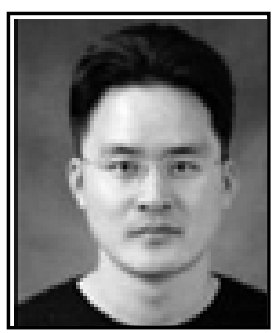

Chin-Chol Kim received a B.S. degree from Hanbat National University, Daejeon, Korea, in 1997, and M.S. and Ph.D. degrees in Computer Engineering from Konkuk University, Seoul, Korea, in 1999 and 2003, respectively. Since 2003, he has been with the Big-data Team, IT Convergence Service Dept., Digital Infrastructure Division, National Information Society Agency, Seoul, Korea where he is currently director of team. His research interests include wire-wireless communication service, QoS, QoE, IPTV, bigdata.

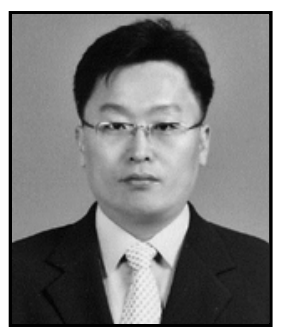

Jong-Pil Jeong received his B.S. degree in Engineering from Sungkyunkwan University and the M.S. and Ph.D. degrees in Computer Engineering from Sungkyunkwan University, Suwon, Korea, in 2003 and 2008, respectively. He was a Research Professor with Sungkyunkwan University in 2008-2009 and 2011, and a visiting professor with the Department of Interaction Science in Sungkyunkwan University in 20092010. He started his academic profession at Sungkyunkwan University, Korea in 2012 as an assistant professor. His research interests include mobile computing, mobility management for vehicular networks, sensor networking, protocol operation based performance analysis, Internet security, MIPv6 and ubiquitous computing.

Jae-Young Choi received his B.S. degree in Mathematics in 1995, and the M.S. and Ph.D. degrees in Computer Science in 1999 and 2004 from the Kyungwon University, Korea, respectively. From 2004 to the middle of 2006, he joined the Vision Laboratory at the University of California, Los Angeles, USA, as a postdoctoral researcher. He has also served as a BK21 research professor at Kyungwon University from 2006 to 2010. Since 2010, he has been an associate professor on contractual basis with the Department of Computer Engineering, College of Information and Communication Engineering at the Sungkyunkwan University, Suwon, Korea. His research interests include computer vision, picture quality, ubiquitous computing, network management, and R\&D strategies. 